\title{
SUPPLEMENTARY MATERIALS WITH THE LOCAL STORIES FOR EXTENSIVE READING ACTIVITY FOR THE NINTH GRADE OF SMP
}

\author{
Norra Dilla \\ Sekolah Menengah Pertama 1 Sukadana \\ Email: missnorraqadrie@gmail.com
}

\begin{abstract}
Abstact
This study aims at developing supplementary reading materials with local values of Sukadana for extensive reading activity designed for the ninth grades students of SMPN 1 Sukadana. Using research and development model adapted from Hyland (2003) and stages of materials development model adapted from Tomlinson (2012) as the bedrock of the study, supplementary reading materials containing four local stories is produced. The pictures and illustrations laid were able to assist the students in understanding the texts and also to attract them to read. The students are expected to use this product as additional materials for extensive reading activity since such materials are not available in their school library and in the market. In addition, teachers can implement Extensive Reading activity by utilizing this product since it can help the students to read more fluently and to expand their knowledge.
\end{abstract}

\section{Key words: Supplementary Reading Material, Local stories, Extensive Reading}

\section{INTRODUCTION}

Reading, which is one of the four language skills being taught in English subjects in school, plays an important role in acquiring English. To accommodate the needs of the students reading skills, the standard of competence and basic competence are formulated in the Standard of Content for each grade. Consequently, the students learn to read based on what has been directed from the curriculum. Reading, however, can be defined variously by many language experts.

Cline et al. (2006) define reading as decoding and understanding text for particular reader purposes. Reading itself, however, will vary according to the purpose of reading since different purposes to some extent will need different strategies in reading. For instance, the one who reads for pleasure will read differently from the one who reads to answer comprehension questions. Weaver (2009) further asserts that those conditions in reading can affect confidence, fear,anger, defiance, and/or other emotions. Therefore, it is important to create an enjoyable atmosphere for reading in order to help the students to understand the text better. To create such an enjoyable atmosphere while reading, extensive reading can be a tremendous alternative for it. Krashen (1982) argues that extensive reading activity will lead the students to acquire language. Extensive reading aims at helping the students to become better at the skills of reading since when the students read extensively, they read very easy, enjoyable books to build their reading speed and reading fluency. Accordingly, Day (2008) showed the result of the study of Extensive

Reading piloted by Sheu (2003) in Taiwan, and Nishono (2007) in Japan. Both studies came to an upshot of increasing reading competence. However, Extensive Reading is rarely implemented in Indonesia, especially in the teaching of English at elementary or high school level. Hence, it is worth developing supplementary materials which are simultaneously designed to be an extensive reading activity by providing the students with various texts. Besides, it is going to be more meaningful and useful to start administering Extensive Reading from the early grade of Junior High, that is, seventh and eighth grade.

In addition to the micro reading skills, Munby (as cited by Grellet, 1983) mentions the following skills: recognizing the language, deducing the meaning, understanding explicit information, understanding implicit information, understanding conceptual meaning, understanding the 
communicative utterances, understanding relations within the sentence, understanding relations between the texts, understanding grammar, interpreting text, recognizing indicators in text, identifying the main idea of text, distinguishing the main idea from supporting details, summarizing the texts, extracting relevant points, skimming, scanning.

From these reading skills, the researcher only picked one reading skill namely understanding explicit meaning since it goes in line with the reading basic competence of the second semester of the ninth grade.

To fulfill the necessity of extensive reading implementation and also the students' interest in reading, good reading materials should be created. The availability of interesting materials is hard to find in SMPN 1 Sukadana and the use of the internet which is actually aimed to facilitate their needs cannot be maximally used. In addition, the availability of reading books in the school. Library only concerns intensive reading. In addition, some factors seem to affect students' reading activity in a rather unfavorable way.

Based on informal interviews in SMPN 1 Sukadana to some students of ninth grades, the researcher found three factors that cause the unfavorable condition. Firstly, the course book does not maximally accommodate the students'need to expand their reading competence. Secondly, it appears that the selected texts in the course book cannot interestingly stimulate the students' motivation to read more enthusiastically since the texts are monotonous. Thirdly, the materials are not local based materials where the students are unfamiliar with the stories so it's hard to them to have a prior knowledge about the story they are going to read.

In SMP 1 Sukadana, particularly in IX-C class, the teaching of reading was mostly focused on translation. The students were drilled to translate English texts into Indonesian. This sort of reading activity should no longer be used according to the curriculum; therefore, the present study can change the paradigm of teaching reading employed by the English teachers of SMPN 1 Sukadana. Supplementary material for extensive reading in the market, especially in Sukadana, cannot be found easily. There are no bookstores in Sukadana and the libararies have so limited book stories. The suitable reading materials for the junior high school students are hard to find, the course book is only designed reading materials for the intensive reading purpose only, not for the extensive reading.

Therefore, supplementary materials for extensive reading are needed by the students. Consequently, the researcher decided to develop a supplementary book in which local stories are incorporated to be read as an extensive reading activity by junior high school students. These local stories are found in "Seri Cerita Rakyat Tanah Kayong" written by M. Dardi D.Has which are translated into English by the researchers and accompanied by illustrations that are painted by the researcher. The involvement of the local stories are expected as the bridge to the knowledge of the students with the materials that they are going to read and also expected by the researcher as one way to preserve the local stories of Sukadana that are long forgotten by the youth in this regency.

The word ,culture comes from the Latin cultura stemming from colere, meaning ,to cultivate $^{\text {ee }}$ a term that has some different meanings (Supartono, 2004:3). According to Louise (1987), there are several notable characteristics of culture that have been woven and rewoven into definitions and the theories upon which they are built: (1) Culture is learned. If it can be learned, it can be taught or acquired; (2) Cultures and cultural patterns change. It is more important to learn how to learn a culture or adapt to these changes than to learn the "facts" and "truth" of the moment. Culture is a universal fact of human life. There is no human group or society without culture. Cultural patterns and themes are related to universal human needs and life conditions; (3) Cultures provide sets of unique and interrelated, selected blueprints for living and accompanying sets of values and beliefs to support these blueprints. Strong networks of relationships and meaning link these blueprints and values systems. These networks provide life support systems for those who interact within them.

Language and culture are closely related and interactive. Culture is transmitted in great part through language. Cultural patterns in turn are reflected in language. 6. Culture functions as filtering device between its bearers and the great range of stimuli presented by the environment. This filtering device is both protective and limiting. Intercultural communicators must traverse the 
boundaries of their own filtering systems or screens and enter the systems of others.

Culture-Based Learning. Culture-based learning can be said as a representation of contextuallearning approach. Contextually, the learning process should be relevant to the real situation and the culture where the learners are. The culturebased itself encompasses all principles, norms, and such practical orientation which exist among the society. This evidence then is used as the orientation in developing the reading material; culture-based reading material is referred to the use of material taken from Sukadana culture. In line with this case, the learning process will be more beneficial and interesting for the learners in Bali since it directly applies their daily lives.

Based on constructivism theory developed by Piaget (in Richardson, 1997), every individual has his own definition toward his learning and he will relate it to his prior knowledge. A learner, moreover, will achieve such knowledge through the process of adding, modifying, renewing, and revising all the information during his learning. Constructivism theory also strengthens that every individual exactly bring along his prior knowledge during the learning. Having such relevance among the new information, the prior knowledge possessed, and both inner and integrated understanding will surely create a meaningful and an effective learning process. Brooks \& Brooks (1993) state the culture-based learning which goes along with the constructivism theory will create such a very convenient learning process. A teacher is more playing a role as a professional educator; helping the learners to do some of the following things: (1) Seeing the relevance between principle of the subject matter and the different culture context; (2) Understanding all the subject matter and the culture where the learners are; (3) Actively participating in the culture-based learning process; (4) Having the learners "e knowledge and experience by varying the classroom activities. Understanding the nature of culture as such community where the learners are being learned and as it is seen from the educational point of view; (5) Having an understanding and being competent to perceive all things around the learnerse daily lives.

Reading is about understanding written texts. It is a complex activity that involves both perception and thought. It is also said that reading consists of two related processes: word recognition and comprehension. Further, Pang et al. (2003) stated that learning to read is an important educational goal for children and adults because the ability to read opens up new worlds and opportunities. So, it enables students to gain new knowledge, enjoy literature, and do everyday things that are part and parcel of modern life, such as, reading the newspapers, job listings, instruction manuals, maps and so on. Supporting the above explanation, Winch et al. (2006) appointed that Reading is the process of constructing meaning from a text, whether written or graphic, paperbased or digital.

The text may be wholly-printed as in most novels, or contain visual elements such as illustrations, diagrams, maps, and graphs as in most children se books and many information books, magazines, and newspaper. Further, Winch et al. (2006) stated that children begin moving along the road to literacy before they come to school. They begin the journey on the day they are born from the first time they hear a human voice. Talk leads them into making a range of meanings with spoken language and it leads them into written words and into books.

However, According to Ross et al. (1996), children who do not understand the important of learning to read will not motivated to learn. Learning to read takes efforts, and children who see the value of reading in their personal activities will be more likely to work hard than those who fail to see the benefits. It means that teacher should consider about these problems and should be willing to do some efforts to conduct the students to be well motivated in learning to read.

Criteria of a Good Material. Materials are defined as anything used to help to teach language learners. Materials can be in the form of a textbook, a workbook, a cassette, a CD-Rom, a video, a photocopied handout, a newspaper, a paragraph written on a whiteboard; anything which present or informs about the language being learned (Tomlinson, 1998).

According to Howard and Major (2005), there are six keys that participants need to take account when embarking on the design of teaching material for their learners, such as: (1)Learners, 
(2)Curriculum and the context, (3) Resources and facilities, (4) Personal confidence and competence of the teachers, (5) Copyright complaints, (6) Time

Further they offer guidance in developing material for ESL students that there are some points should be considered, such as: (1)English Language Teaching materials should be contextualized; (2) Materials should stimulate interaction and be generative in terms of language; (3)English Language Teaching material should encourage learners to develop learning skills and strategies; (4) English Language Teaching material should allow for a focus on form as well as function; (5) English Language Teaching material should offer opportunities integrated language use; (6) English Language Teaching material should be authentic; (7) English Language Teaching material should link to each other to develop a progression of skills, understanding, and language use; (8) English Language Teaching material should be attractive; (9) English Language Teaching material should have appropriate instructions; (10) English Language Teaching material should be flexible.

In line with the guidelines of developing material, Tomlinson (1998: 7-21) explains some principles of second language acquisition relevant to the development of materials for the teaching of language. They are: (1)Material should achieve impact; (2) Materials should help learners to feel at ease; (3) Material should help the learners to develop confidence, what is being taught should be perceived by learners as relevant and useful; (4) Materials should require and facilitate learner selfinvestment; (5) Learner must be ready to acquire the points being taught,; (5) Materials should expose the learners to language in authentic use; (6) The learners"e attention should be drawn to linguistic features of the input; (7) Materials should provide the learners with opportunities to use the target language to achieve communicative purposes; (8) Materials should take into account that the positive effects of instruction are usually delayed; (9) Material should take into account that learners differ in learning styles; (10) Materials should take into account that learners differ in affective attitudes; (11) Material should permit a silent period at the beginning of instruction; (12) Material should maximize learning potential by encouraging intellectual; (13) Material should not rely too much on controlled practice; (14) Material should provide opportunities for outcome feedback

However, not all principles above can be used in designing reading material because those are used when the material researchers want to develop the material in general which include four skills (listening, speaking, reading, and writing). The principles above should be summarized again and adjusted with the need of developing reading material.

\section{METHOD}

This study was designed as Research and Development (R\&D) with research model adaptation proposed by Hyland (2003). This research model covers a set of stages starting from needs assessment, developing materials, experts and teachers validation, revision I, small group tryout, revision II, to final product. Needs assessment was carried out to find out the actual learners' needs focusing on (1) identifying the students' previous learning experiences; (2) obtaining information dealing with a particular problem/difficulty that learners are experiencing in reading; (3) identifying students' preferences and interest about the materials to be developed; and (4) probing the students' frequency of reading. To obtain the answers, the researcher used questionnaires distributed to the students, and interviewed the teacher.

After conducting needs assessment, the data obtained were analyzed descriptively and quantitatively, and then the researcher commenced developing the product based on the analysis. Materials development featured two stages namely drafting and organizing. Drafting phase includes (1) designing the content; (2) selecting the topic of texts; and (3) determining the reading skills. After the stage of drafting was accomplished, the researcher then continued to the organizing stage. It features (1) constructing the texts; (2) determining the activities; and (3) making the answer key.

The following stage to establish after developing materials was validation from experts and teachers. The validators were 1) a lecturer of Tanjung Pura University specializing in extensive reading and teaching English as a second language and 2) an English teacher of SMPN 1 Sukadana who had already been teaching for about 15 years. They were needed to constructively criticize the 
materials so that the researcher-writer was able to improve the quality of the materials being developed. The validators' valuable comments were used as the basis on which revision was made. To conduct this stage, the researcher provided a checklist for the expert and the teacher to complete. They were requested to analyze and evaluate the product based on the checklist.

The improvements made after obtaining comments and feedback from the validators are stated as follows. Firstly, the expert suggested that each text should be accompanied by the glossaries of the specific terms used in the stories along with the explanations about the terms used. This will help students to comprehend the text well and the students don't have to come back and forth to the dictionary in order to figure out the meaning. The second suggestion is, since each of the texts are quite long (approximately 900 words for each text), the text should be accompanied with more than one illustration to help students to make sense of the stories and attract their curiosity to keep reading. In addition, the expert further advised to add various kinds of exercises not only the essay form but also more challenging exercise like filling gap activity, matching, and develop the ending of the incomplete stories. This will help the readers to develop their critical thinking that will lead into high order thinking skill. The layout of the book should be more interesting and eye-catching and should be printed in a better paper quality. After the validation and revision were managed, the product was then ready for the try-out.

The product was tried out to the 10 randomly chosen students of IX Cof SMP 1 Sukadana. The product was distributed to them to be read at home. The researcher gave time allocation for the students to read the materials for three days. Trying out the product was conducted in order to identify the suitability, acceptability, and some weaknesses of the materials. The weaknesses found were used to improve the quality of the materials. To know the quality of the materials the researcher distributed a questionnaire to the students. It covered: the level of difficulty, attractiveness of the texts, variety of exercises, clarity of the instructions, and the content of the product. After obtaining the data from the try-out, the researcher then scrutinized them descriptively and used them as the consideration of revision. The researcher also focused on students' comments and feedback in order to make some improvement for the product.

\section{FINDINGS AND DISCUSSIONS Findings}

The product try-out was undertaken on April 8th, 2019. The first aspect that needed to be investigated from the students was design and layout. Most of them were interested in the design of the book. They stated that the size of the book that is portable makes them easier to carry. In addition, most of the students were appealed by the illustrations provided. Some of their comments indicated that this product at least already achieved one of the criteria of good materials which had already been determined at need assessment stage, that is, the materials were attractively designed.

The second point of the result of the try-out dealt with suitability and exploitability of the content. Suitability of the content was still categorized into two points, namely: topic and language features. For topic suitability, 6 out of 10 students argued that the topics were suitable, 3 out of 10 students stated that they were suitable enough, and only 1 student mentioned that the topics were not really suitable. For the language features, most of the students argued that they were adequately suitable for their reading competence. Furthermore, exploitability of the content here was related to whether or not the texts provided were able to expand students' knowledge as well as to make students understand the target language fluently. Based on the try-out questionnaire, it showed that most of the students had reason that the texts were able to expand their knowledge as well as trigger their willingness to read them.

The third worth-elaborating aspect is about variation of text-types and exercises. The result showed that the criterion of variation of text-types had already been fulfilled. In addition, the exercises provided to understand the texts were considered enough according to the students. However, even the exercises interestingly and attractively triggered the students to do them, the exercise are not challenging enough and tend to be monotonous. But, they came to enjoy reading the texts. They claimed that they had become more knowledgeable about Sukadana's local stories that they have never known or heard before. One of the students even 
used one of the stories to join the English Story Telling contest and won a first prize.

The fourth point deals with the level of difficulty, which covered three general points, namely: the length of the text, the diction, and the exercises.

Concerning the length of the texts, only one student argued that some of the texts were too long so that he felt a bit bored while reading. Concerning the diction used in the texts, some of the students still faced difficulty dealing with the choice of words although at the end of chapter there are glossaries. Moreover, exercises provided in the text were still doable independently for the students.

After administering try-out of the product, the result of questionnaire distribution at try-out phase was used as the consideration of revision. The first revision was about the choice of font-style. At first, there were only two kinds of font-style used in the product; those are Garamond and Script MT Bold in order to give an artistic touch, but then some students suggested to use other various font-styles. Accordingly, the researcher revised it and used other font-style such as Berlin Sans FB, Bell MT, Book Antiqua and Euphemia.

Next, some of the students still faced difficulty in understanding some dictions or vocabulary items. Therefore, the researcher still changed some words which were considered difficult. In addition, to help students to understand some vocabulary items, eventually, the product included glossaries at the end of each chapter. However, the glossary was still monolingual and it somehow still confused the students who were trying to understand the items. Accordingly, the glossary was then revised into bilingual one, that is, English-Indonesian.

\section{Discussions}

The upshot of this study was a printed supplementary material designed for Extensive Reading activity entitled "Seri Cerita Rakyat Tanah Kayong that is translated into "The Famous Local Folklores In Kayong Land". The product features three chapters: (1) Story 1 (The Tale Of Sandah Kekiwi), (2) Story 2 (Hantu Sengkuman The Iron Eater); (3) Story 3 (The Tale Of Hantu Dendam Buak), (4) Story 4 (The Tale Of Kak Keling) and Story 5 (The Tale Of Putri Bungsu).

The material consists of 5 texts, which focus on one reading skill namely understanding the explicit meaning. This goes in line with basic competence which is to understand the explicit meaning perfectly and efficiently written functional and simple short essay texts in narrative related to the surrounding environment or in academic context.

After the product try-out, some strengths and conceivable weaknesses of the product were known. The first strength is that this product is exclusively designed for Extensive Reading activity. It is supported by Bamford and Day (1998 in ER Foundation) who asserted that when the students read extensively, they actually read very easy and enjoyable books to build their reading speed and fluency.

Secondly, this product provides local based cotent text types: narrative, descriptive and expository. For some students who have ever heard the stories, the text provides prior knowledge to them and for those who are unfamiliar with the stories conveyed in the texts, the texts are informative, challenging, and raising their curiosity to keep on reading. The research provides each of the texts consists of approximately 900 words but this length doesn't not discourage the students to read because of the stories are interesting.

Thirdly, the activities are not considered as burdensome. This product promotes an edutainment activity. It means that any contents of this product focus on educating students as well as entertaining them. It is in line with Krashen (1984) who states that reading should be done enjoyably and students should feel motivated to read more if they feel they read well. This edutainment activity, for instance, appears in an activity dealing with crossword puzzle. In doing the crossword puzzle the students answer the comprehensive questions which represent educating activity and at the same time they are also doing game as entertainment activity.

Fourthly, in terms of layout and design, this product is attractive. The size of the product is 14.5 $\mathrm{cm} \times 21 \mathrm{~cm}$; it means that this product is so portable. In addition, colors and pictures make this product more attractive and importantly help the students to understand the texts more easily. It is proven by some comments mentioned by the students at the try-out process. One of them claimed that the developed product brings pleasure and is able to broaden his knowledge. 
Nonetheless, several weaknesses may appear in this product of study. In terms of the number of texts, the product only consists of 5-long-texts. It may not be adequate since the students are expected to read more. However, this condition is because of time limitation and production cost.

Another weakness is that this product is in the form of printed-media. To some extent, the printer device affects the quality of printing. It makes some of the pictures or illustration unclear to the readers' eyesight. However, this product is an alternative medium for the ones who do not like reading on the computer screen. In addition, not all students have computer device as their learning medium. The researcher believes that this product still needs improvement in terms of many aspects. This product, however, can be used as reference for the ones who are going to conduct similar study so that in the future a better innovation for this product looks assured.

\section{CONCLUSIONS AND SUGGESTIONS Conclusions}

The texts in the supplementary material for reading are informative since they inform the week. Hence, increasing the number of texts is highly recommended so that the students can be more skillful particularly in reading.

Furthermore, this product is in the form of printed book. It may be better for future researcherwriter to upgrade the product into the form of ebook or even sort of Macromedia Flash to attract students' motivation in reading as well as to reduce the production cost. With all those possibilities, extensive reading activity can be more enjoyably conducted.

In addition, in order to achieve more valid qualification of the acceptability of the product, it is worth trying-out the product more than once and also to expand the numbers of population in following studies.

\section{REFERENCES}

B, Tomlinson. Materials Development for Language Learning and Teaching. Cambridge: Press Weaver, 2009.

Extensive Reading Foundation. (2011). Guide to extensive reading. Retrieved from http://erfoundation.org/ERF Guide.pdf students about the target language and some unique information to broaden their knowledge. The product also has already reached qualification in suitability and acceptability, that is, the texts and the activities enable the students to learn English more easily and enjoyably. The vocabulary items used were also appropriate to the students' level of reading comprehension ability. The pictures and illustrations laid were able to assist the students in understanding the texts and also to attract them to read. The students are expected to use this product as additional materials for extensive reading activity since such materials are not available in their school library and in the market. In addition, teachers can implement Extensive Reading activity by utilizing this product since it can help the students to read more fluently and to expand their knowledge.

\section{Suggestions}

A suggestion for future researcher is that this book still needs expansion. This particular product contains 5 texts with a rough assumption that the students are going to read extensively once in a

Ferdila, Raihani. "The Use of Extensive Reading in Teaching Reading." Journal of English Education , 2014: 68-80.

G.M, Jacobs. "Selecting Extensive Reading Materials." Selecting Reading Materials, Beyond Words, May 8, 2014: 116-131.

J, Bamford, and Day R.R. Extensive Reading in the Second Language Classroom. Cambridge: Cambridge University, 1998.

Krashen. Principles and Practice in Second Language Acquisition. Oxford: Pegamon Press, 1984.

Kusuma, I Putu Indra. "Developing Reading Material for Elementary Students in Tourism Area by Inserting Local Culture." JEELS, Volume 3, number 1, 2016: 109-127.

Renandya, W. A. (2007). The power of extensive reading. RELC Journal, 38, 133-149.

S.D, Krashen. Second Language Writing. Cambridge: Cambridge University Press, 1982. 
